\title{
Urinary tract infections after renal transplantation: Do they matter?
}

\author{
P J A GRIFFIN, J R SALAMAN
}

British Medical Fournal, 1979, 1, 710-711

\section{Summary and conclusions}

The effect of urinary tract infections on renal function was assessed in 86 patients with renal allografts that had functioned for more than one year. Follow-up periods ranged from one to 10 years. Recurrent or persistent urinary sepsis was quite common in these long-term survivors but had no observabie effect on graft function or survival of patients or grafts. Treatment of asymptomatic urinary tract infections was largely unsuccessful. Probably such infections may be safely ignored.

\section{Introduction}

Chest and wound infections in renal transplant recipients may be serious complications and a major cause of death. ${ }^{1-3}$ Conversely, urinary infections are relatively benign, ${ }^{4}$ though fatal complications have occurred ${ }^{2}$ and it is usual practice to institute vigorous treatment with antimicrobial agents. Recurrence of infections is common and many courses of treatment may be required. We have found for some time, however, that urinary tract infections cause very little trouble and that treatment is not only ineffective but probably unnecessary. We therefore conducted the following analysis to see whether this impression was valid.

\section{Patients and methods}

All patients who received renal allografts during 1967-77 were reviewed. Those who died or lost their grafts within the first year after transplantation were excluded. Kidneys were obtained from cadavers or live related donors and transplanted into the iliac fossa. The renal vessels were anastomosed to the external iliac vessels and the ureter implanted into the dome of the bladder in a manner designed to prevent reflux of urine. In earlier years this was splinted with a ureteric catheter but in later cases a splint was not used. A urethral catheter was inserted immediately preoperatively and removed after 48-72 hours. The operation site was drained by two suction drains.

Immunosuppressive agents used were azathioprine and corticosteroids. At the time of operation each patient received azathioprine $(5 \mathrm{mg} / \mathrm{kg})$ and methylprednisolone $(1 \mathrm{~g})$ intravenously. Subsequently azathioprine $(2 \mathrm{mg} / \mathrm{kg})$ and prednisolone $(2 \mathrm{mg} / \mathrm{kg})$ were given by mouth, the prednisolone being gradually reduced to a maintenance dose of $10-15 \mathrm{mg}$ daily. A few patients received antilymphocyte globulin (Burroughs-Wellcome) during the first 10 days. Follow-up after the first year was at three-month intervals. At each visit blood pressure, temperature, and weight were measured. Blood was taken for full cell count and urea, electrolyte, and creatinine estimations. Urine collected over the previous 24 hours was used to calculate creatinine clearance. A midstream specimen was obtained for culture and sensitivity tests, the urine being regarded as infected if the bacterial count exceeded $100 \times 10^{6}$ organisms/l. Since most patients had white cells in the urinary deposit their presence was not taken to indicate infection. Urinary infections were treated with appropriate

Renal Transplant Unit and KRUF Institute of Renal Disease, Royal Infirmary, Cardiff CF2 1SZ

P J A GRIFFIN, MB, FRCS, research registrar

J R SALAMAN, MCHIR, FRCS, director of renal transplant unit antimicrobial agents in courses of one to two weeks. If the infection persisted or recurred after two or more courses and the patient was free of symptoms no further treatment was given. In some cases of persistent symptomatic infections bilateral nephrectomy was performed.

\section{Results}

Eighty-six patients receiving renal allografts between June 1967 and July 1977 were reviewed. In cases in which two grafts were given only the second is considered here. Fifty-five of the patients were male and 31 female and their mean age was $36 \cdot 6$ years (range 14-59 years). Table I lists the original renal diseases and numbers of patients with infected and sterile urine. Of those whose original renal disease was associated with infection, $61 \%$ developed urinary infections after transplantation, whereas of those whose original disease was not associated with infection, $35 \%$ developed postoperative urinary infections. There was also a preponderance of women in the infected group $-63.6 \%$ compared with $36.4 \%$ in the sterile group.

One-fifth of the 86 patients acquired urinary infections by six months after transplantation, and a further fifth became infected during the subsequent years (fig 1). In long-term survivors no new infections occurred after six years. Fig 2 shows the periods during which patients were infected. Transplant function in the infected group was compared with that in the sterile group by analysing the serum creatinine values obtained at yearly intervals. No significant differences were found. There was also no significant difference between the two groups in patient and graft survival (fig 3). Of all 36 patients who acquired urinary infections, 30 were alive with functioning grafts, 15 of whom had persisting urinary tract infections. Table II shows the causes of graft loss in the infected and noninfected groups.

TABLE I-Diseases causing failure of patients' own kidneys and numbers with sterile and infected urine

\begin{tabular}{lcccccc}
\hline \multicolumn{3}{c}{ Causes of failure of patients' own } \\
kidneys
\end{tabular}

${ }^{*}$ Chronic atrophic childhood pyelonephritis. ${ }^{10}$

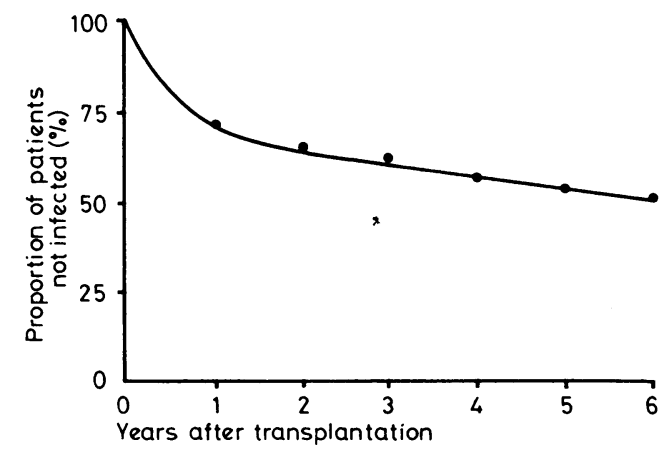

FIG 1-Proportions of patients whose urine remained sterile after transplantation. 


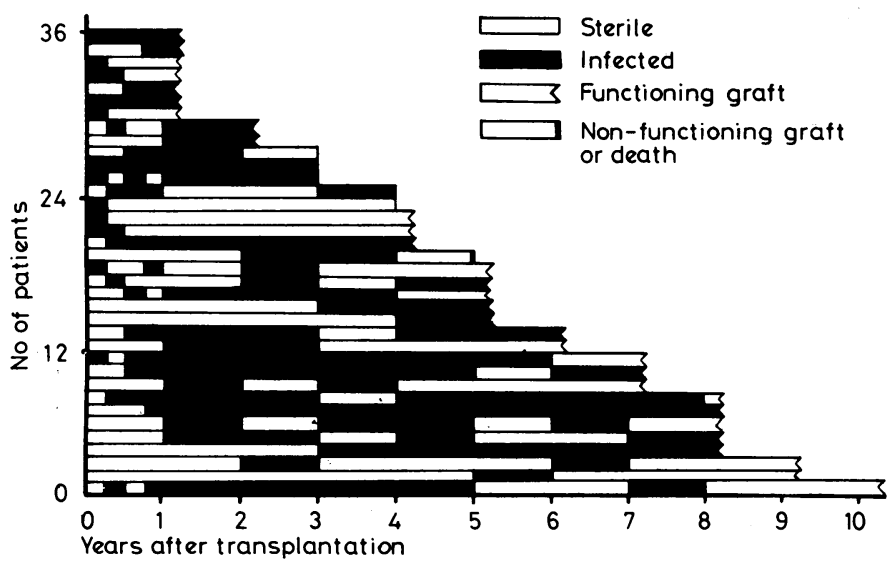

FIG 2-Times of infection in 36 patients whose urine became infected after transplantation.

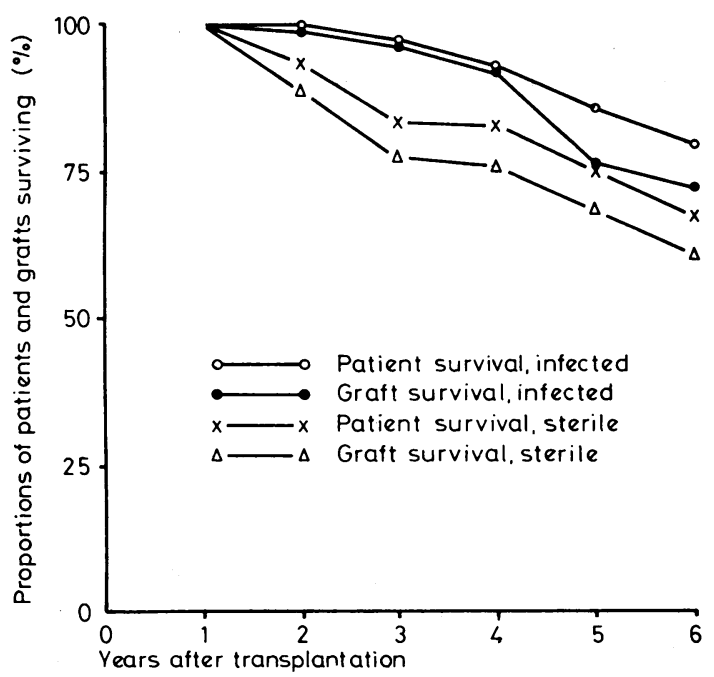

FIG 3-Proportions of patients and grafts surviving after transplantation.

TABLE II-Reasons for graft loss in long-term transplant recipients

\begin{tabular}{|c|c|c|c|}
\hline Causes of graft loss & & $\begin{array}{l}\text { Urine infected at } \\
\text { some time }\end{array}$ & $\begin{array}{c}\text { Urine always } \\
\text { sterile }\end{array}$ \\
\hline $\begin{array}{l}\text { Chronic rejection } \quad \ldots \\
\text { Acute rejection } \\
\text { Death with functioning graft }\end{array}$ & $\begin{array}{l}\ldots \\
\cdots\end{array}$ & $\begin{array}{l}2 \\
4\end{array}$ & $\begin{array}{l}6 \\
1 \\
7\end{array}$ \\
\hline
\end{tabular}

Nineteen patients had had their own kidneys removed either before or after transplantation. Five had bilateral nephrectomies because of infective complications and 14 because of uncontrolled hypertension. Six further patients had a unilateral nephrectomy at some time before transplantation because of chronic symptomatic infections. Of the five patients who had bilateral nephrectomy for infection, only two-both male-were cured, their urine being rendered sterile.

Patients who had urinary tract infections at some time suffered a much higher incidence of postoperative complications associated with the transplant $(41.6 \%)$ than did patients whose urine was always sterile $(6 \%)$. Rejection episodes, however, were no more frequent. Table III lists the organisms responsible for each infection, relapses being defined as recurrent infections with an organism having the same antibiotic sensitivity, reinfections being due to either different organisms or similar organisms with different sensitivities.

Thirteen patients had vesicoureteric reflux of their own urinary tracts, $6(17 \%)$ in the infected group and $7(14 \%)$ in the sterile group. Of these, seven underwent nephrectomy, leaving three patients in each group with refluxing urinary tracts.
TABLE III-Organisms responsible for urinary infection after transplantation

\begin{tabular}{|c|c|c|c|c|}
\hline \multirow{2}{*}{ Organism } & & \multirow{2}{*}{ First infection } & \multicolumn{2}{|c|}{ Subsequent infections } \\
\hline & & & Recurrences & Reinfections \\
\hline $\begin{array}{l}\text { Escherichia coli } \\
\text { Streptococcus faecalis } \\
\text { Proteus .. } \quad . \\
\text { Candida . . } \\
\text { Staphylococcus } \\
\text { Psureus } \\
\text { Pseudomonas } \\
\text { Mixed growth }\end{array}$ & $\begin{array}{l}\ldots \\
\because \\
\cdots \\
\cdots \\
\cdots\end{array}$ & $\begin{array}{r}21 \\
9 \\
4 \\
1 \\
1\end{array}$ & $\begin{array}{r}13 \\
4 \\
4 \\
1 \\
1 \\
2\end{array}$ & $\begin{array}{l}3 \\
6 \\
4 \\
1 \\
2 \\
4\end{array}$ \\
\hline
\end{tabular}

\section{Discussion}

The major early complications after renal transplantation are infection and graft rejection, infections being a major cause of death. ${ }^{135}$ Urinary tract infections are particularly common immediately after operation and are usually confined to the lower urinary tract. ${ }^{8}$ These infections are probably related to catheterisation ${ }^{1}{ }^{2}$ and, although usually mild, may result in death. ${ }^{2}$ We looked for harmful effects of infections occurring later after transplantation. Of the 86 patients who had survived for more than one year after operation, $36(42 \%)$ had developed urinary tract infections. Many patients had no symptoms and none of the infections led to serious complications or death.

Patients whose urine had been infected before transplantation tended to have more infections after the operation, and the response to short courses of treatment was disappointing, many cases of relapse as well as reinfection occurring. Patients whose original urograms had shown coarse kidney scars were predominant in this group, and were mostly women. These findings agree with those of others. ${ }^{4} 8$

Bilateral nephrectomy before or at transplantation is common in the United States. ${ }^{5}$ We undertake this operation when clinically indicated, but in the few patients in whom it was done urinary infections were not always prevented. Vesicoureteric reflux in the patients' own urinary tracts seemed to be unrelated to the occurrence of postoperative infection. No differences in renal function could be detected between the two groups of patients. The mean serum creatinine concentrations in patients with sterile urine tended to be lower, but not significantly so, than in patients whose urine was infected at some time. Some infections may trigger rejection episodes, ${ }^{9}$ but in our series there was no greater incidence of rejection in the infected group.

We think that these findings confirm our clinical impressions -namely, that in long-term survivors after renal transplantation asymptomatic urinary tract infections do not seem to matter so far as graft function is concerned. Most infections return after short courses of treatment with antimicrobial agents and it seems that repeated attempts to erradicate such infections are unnecessary.

We thank Professor A W Asscher for invaluable help in preparing this manuscript.

\section{References}

${ }^{1}$ Sussman, M, and Russel, R B, Proceedings of the Royal Society of Medicine, $1972,65,471$.

${ }^{2}$ Martin, D C, Archives of Surgery, 1969, 99, 474.

3 Kelly, W D, et al, Surgery, 1967, 62, 704.

${ }^{4}$ Hampshire, R J, Chisholm, G D, and Shackman, R, Lancet, 1974, 2, 793.

5 Burgos-Caldom, R, Pankey, G A, and Figueroa, J E, Surgery, 1971, 70, 334.

6 Prat, V, et al, Proceedings of the European Dialysis and Transplant Association, 1976, 13, 200.

7 Walter, S, Pedersen, F B, and Vejlsgaard, R, British Fournal of Urology, 1975, 47, 513.

${ }^{8}$ Leigh, D A, British fournal of Urology, 1969, 41, 406.

9 Simmons, R L, et al, Transplantation Proceedings, 1970, 2, 419.

${ }^{10}$ Hodson, C J, and Wilson, S, British Medical fournal, 1965, 2, 191. 